«Возьми, царь, последнего... У меня уж никого не осталось...» - а также непритворное благочестие: «(Крестится): Царство небесное Петру и Николаю! Поди позови священника в церковь...» (Там же. С. 112-113). Финал пьесы, тем не менее, в отличие от большинства современных ей, минорен: никто не уверен, что последний сын вернется домой.

Пьеса Писемского, поставленная на сцене, когда эйфория первых побед спала, очевидно, оказалась созвучна переживаниям многих. Об этом свидетельствует то, что она не только обрела популярность публики, но и сама спровоцировала подражания. Об этом, сопоставляя театральные постановки Писемского и драму «г. Миллера» с выспренным названием «Подвиг матери», напоминает рецензент «Отечественных записок»: «Читатели наши <...> еще не забыли произведения г. Писемского, которое $<\ldots>$ напечатано в сентябрьской книжке нашего журнала за прошлый год, и содержание пьесы г. Миллера чрезвычайно похоже на "Ветерана и новобранца"» (О3. 1855. № 2. С. 172). Подражатель, взяв за основу чужой сюжет, решил «сыграть» на усилении мелодраматизма. В центре у него оказывается всеобщая «сцена скорби» при получении рокового известия о смерти двух сыновей. Он заменил отца-ветерана матерью, дублировал центрального персонажа (мать) образом убитой горем «молодой жены» одного из погибших, ввел «оставленную невесту» и патетическую сцену прощания с нею последнего из братьев и т. д.. Патетика, однако, как и преувеличенный восторг первых пьес, не встретила понимания публики.

Сопоставление с предшествовавшей и последовавшей драматической беллетристикой, при сюжетной и идейной близости, как нам кажется, убеждает в том, что «Ветеран и новобранец»

УДК821.161.1.09 : 159.922.1

\section{МАТЕРИНСКО-ДОЧЕРНИЙ МЕТАСЮЖЕТ РУССКОЙ ЖЕНСКОЙ ПРОЗЫ}

\section{Н. И. Павлова}

Тверской государственный технический университет E-mail: nadija_80@mail.ru

В статье рассматривается проблема материнско-дочерних отношений как одна из центральных в истории женской литературы. На основе сравнительного анализа произведений писательниц разных историко-литературных эпох выявлены общие закономерности ее репрезентации, знаменательные в аспекте изучения специфики женской литературы и эстетики.

Ключевые слова: материнско-дочерние отношения, образ матери, женская литература, феминистский психоанализ, современная женская проза.
Писемского оказался выше уровня современных патриотических пьес - по тональности и благородной скупости рисунка.

Пьеса продолжает размышления писателя о природе человеческих страстей. «Ветеран и новобранец» занимает важное место в творческой эволюции его автора, представляя положительный полюс драматургического поиска, позволяет говорить о наличии положительной программы писателя.

\section{Примечания}

1 Писемский А. Письма / под ред. и комм. М. К. Клемана и А. П. Могилянского. М. ; Л., 1936. С. 72.

2 Там же.

3 См.: Отечественные записки. 1854. № 9. Отд. 1. С. 122.

4 Там же. С. 97-122.

5 Писемский А. Указ. соч. С. 73.

6 Отечественные записки. 1854. № 1-2. Отд. 7. Петербургские заметки. С. 136. В дальнейшем все ссылки на указанное издание даются в тексте, с указанием года, номера, раздела и страницы.

7 E.<вгений> Э. $<$ дельсо $>$ н. Отечественные записки. 1854. № 9 и 10 // Москвитянин. 1854. № 22. Кн. 2. Отд. 4. Журналистика. С. 75.

8 Там же.

9 Опираясь на автобиографические заметки Писемского, исследователи указывали, что под именем «ветерана» Алексея Петровича Лихарева был выведен отец писателя, Феофилакт Гаврилович Писемский. См.: Бочков В. Биограф отца // Бочков В. «Скажи : которая Татьяна...». M., 1981. C. 197-206.

10 См.: Moser C. Pisemsky a provincial realist. Cambridge, 1969. P. 27.

11 Аннинский И. Три социальных драмы // Аннинский И. Книги отражений. М. ; Л., 1969. С. 52.

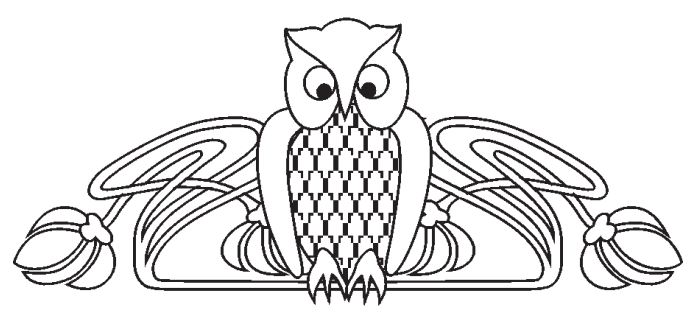

\section{Mother-daughter Meta Plot in Russian Women's Prose}

\section{N. I. Pavlova}

The article deals with the problem of mothers and daughters relationships as one of the central issues in the history of women's literature. On the basis of the comparative analysis of women's texts of different historic and literary epochs, some general tendencies in its representation are identified, which are important from the point of view of researching women's writing and aesthetics. 
Key words: mothers and daughters relationships, mother's image, women's literature, feminist psychoanalysis, modern women's prose.

Свое размышление в рамках данной статьи хотелось бы предварить высказыванием одной из представительниц американского феминизма Адриенны Рич, ставшим хрестоматийным в области феминистской критики: «Катаксис между матерью и дочерью - эссенциалистский, искаженный, пропущенный в использовании - великая ненаписанная история < .. > Еще это отношения, которые минимизированы и упрощены в анналах патриархатного общества» ${ }^{1}$. Выраженная А. Рич идея о значимости природного единения матери и дочери, процесс осознания которого затруднен нивелированием этого пласта человеческих отношений в логосе культуры, выстроенной по мужским законам, очерчивает масштаб проблемы, связанной с ролью матери в процессе женского становления. К тому же он способствует более обстоятельному изучению в данном аспекте женских практик письма, предоставляющих с этой точки зрения богатый материал для анализа. Такого рода попытки впервые были предприняты западными исследователями женской литературы, акцентировавшими внимание на этой проблеме ${ }^{2}$.

Действительно, отношения матери и дочери, по справедливому замечанию как зарубежных, так и отечественных исследователей, представляют собой тот вариант отношений между родителями и детьми, который менее всего становился предметом художественного интереса «большой» литературы XIX в., представленной преимущественно мужскими именами ${ }^{3}$. Между тем этот тип отношений становился объектом пристального внимания уже писательниц первой половины XIX в.: Е. А. Ган, М. С. Жуковой, Н. А. Дуровой, А. Я. Панаевой, А. Я. Марченко и др. Особую значимость проблема взаимоотношений с матерью приобретает в текстах писательниц 1850-1860х гг. в связи с появлением в жизни и в литературе типа «новой женщины» 4 . Углубление данной проблематики происходит в женской прозе конца XIX- начала XX в., когда образ матери становится не только объектом художественного осмысления, но и неотъемлемым атрибутом репрезентации женского опыта. Так, наиболее интенсивное звучание темы материнско-дочерних взаимоотношений можно наблюдать в творчестве таких писательниц рубежа XIX-XX вв., как М. В. Крестовская, Е. П. Леткова, Н. П. Анненкова-Бернард и др. Наконец, высока степень художественно-смысловой значимости данной темы в дискурсе современной женской прозы (в разной степени она присутствует в текстах многих известных писательниц Г. Щербаковой, Л. Петрушевской, Н. Горлановой, Д. Рубиной, М. Вишневецкой, О. Славниковой, М. Степновой и др.). Материнско-дочерние линии повествования, столь отчетливо прослеживающиеся в прозе писательниц разных литературных эпох, существенным образом корректируют взгляд на женскую прозу как литературный феномен, свидетельствуя в пользу потенциальной некоей эстетической доминанты, элемента того, что составляет основу женского художественного миросозерцания, женской практики письма.

В предлагаемой статье мы обратимся к корпусу женских художественных текстов, относящихся преимущественно к концу XIX- началу XX в., поскольку именно в этот период прослеживается тенденция к более подробному и многостороннему исследованию психофизиологической природы материнско-дочерней связи. Более того, актуализированная писательницами данной литературной эпохи проблема материнско-дочерней связи обретает некую автономность, сопутствуя более обширной проблеме поиска женского самоопределения. При этом явный психологический акцент в ее интерпретации обнаруживает тесные параллели с творчеством представительниц современной женской прозы, во многом совпадая с их эстетическими изысканиями, тем самым выявляя некое общее семиотическое пространство в репрезентации женского модуса бытия.

Общим для писательниц отдаленных друг от друга эпох является склонность изображать дисгармоничные материнско-дочерние отношения, окрашенные амбивалентными чувствами «любвиненависти», сильной взаимной привязанностью и безнадежным стремлением преодолеть ее. Именно такой ракурс художественного видения проблемы мы обнаруживаем в литературном творчестве одной из ныне забытых писательниц конца XIX - начала ХХ в. Е. П. Летковой (1856-1937), в котором проблема материнско-дочерних отношений носит устойчивый характер ${ }^{5}$. По признанию самой писательницы, вопрос о «разладе» ${ }^{6}$ между матерью и дочерью всегда волновал ее.

Касаясь разных аспектов взаимодействия матери и дочери, писательница уделяет особое внимание тем процессам, которые происходят в дочернем сознании под воздействием матери и руководят ее поведением, вплоть до определения жизненных стратегий. Конфликт «мать - дочь» в текстах Летковой представлен, главным образом, как конфликт дочернего сознания. Переживания дочери зачастую и становятся предметом повествовательного интереса, являясь одним из способов организации внутреннего конфликта героинь, которые движимы противоречивым чувством привязанности к матери и сопротивления ей. В свою очередь, материнские образы объединяет стремление к самопожертвованию и, как следствие, эгоистическое желание распоряжаться собственными дочерьми. Показателен в этом отношении рассказ Летковой «Отдых» (1896), где повествуется о 42-летней одинокой телеграфистке Марье Ниловне, которая из-за нарастающего ощущения бессмысленности своего незаметного существования кончает жизнь самоубийством. Одно из объяснений внутреннего конфликта героини напрямую связано с характером ее взаимоотно- 
шений с недавно умершей матерью, подчиняясь запретам которой, она так и не устроила свою личную жизнь и «одиноко задавила» ${ }^{7}$ в себе не одно любовное чувство. Представление героини о матери ассоциируется с властью, запретом и несвободой. В тексте неоднократно подчеркивается, что Марья Ниловна всегда действовала из «боязни огорчить мать» ${ }^{\mathbf{8}}$. Эта фраза приобретает значение формулы и для характеристики других женских персонажей Летковой.

Сходную художественную интерпретацию материнско-дочернего конфликта мы встречаем в повести М. В. Крестовской «Вне жизни» (1887), где рассказана история героини, которая не решилась самостоятельно, независимо от материнских советов и наставлений устроить собственную судьбу. Женечка Лидова (так зовут главную героиню) вынуждена повторить жизненный путь своей овдовевшей матери - классной дамы - и навсегда остаться в стенах института, постепенно превращаясь из когда-то юной его воспитанницы в озлобленную старую деву-инспектрису. По сути, героиня Крестовской становится жертвой материнского эгоизма. Привыкшая к размеренному институтскому существованию мать не желает отпустить от себя дочь, всячески внушая ей страх перед самостоятельной жизнью. В свою очередь, «привычка к материнскому авторитету» ${ }^{9}$ побуждала дочь слепо верить в правоту матери.

Заданный вектор развития темы находит продолжение в современной женской литературе. Так, тема «мать - дочь» сходным образом воплощена в творчестве Л. Петрушевской. Одним из выразительных произведений писательницы с этой точки зрения является роман «Время ночь. Записки на краю стола» (1991), в котором взаимоотношения между матерью и дочерью «построены на постоянной взаимозависимости» ${ }^{10}$ и сопряжены с теми же мотивами силы/бессилия, подавления/сопротивления, что и в рассмотренных нами текстах писательниц-предшественниц. Автором показано, как созидательная материнская сила оборачивается разрушительной своей стороной, а чувство любви и опеки граничит с авторитарностью и деспотизмом. Материнское начало, воплощенное в образе главной героини Анны, живущей заботами о взрослой дочери и ее семье, репрезентировано в категориях неограниченной власти и эгоизма. Она мешает своей дочери обрести собственную женскую идентичность, обращая на нее свой гнев и ревность, как только та по мере взросления начинает совершать первые попытки вырваться за пределы материнского контроля. Однако важным оказывается еще и то, что героиня проецирует на дочь свои собственные взаимоотношения с матерью («...о ненависть тещи, ты ревность и ничто другое, моя мать сама хотела быть объектом любви своей дочери, то есть меня, чтобы я только ее любила, объектом любви и доверия. .. ${ }^{11}$ - признается Анна в своем дневнике). Возникающий таким образом мотив повторения, непрерывности женского опыта, женской генеалогии перекликается с наблюдением феминистского психоанализа о том, что мать является как дочерью своей матери, так и матерью своей дочери ${ }^{12}$.

Деструктивное материнское влияние достигает своего апогея в рассказе Петрушевской «Круги по воде» из прозаического цикла «Черная бабочка». Героиня рассказа девочка-подросток Галя, «язва и бич матери» ${ }^{13}$, в буквальном смысле слова становится жертвой безудержного и безоглядного чувства материнского собственности. Мать, всю жизнь грезившая стать балериной, но так и не достигшая «заветной цели, <..> твердой рукой направляла дочь по линии искусства» (55), неустанно терроризируя дочь постоянными замечаниями и упреками. Преподнося подругам свой «подвиг матери» как тяжкий крест, мать постепенно доводит девочку до психического расстройства и шизофрении, усиливая в ней до крайности чувство неполноценности («Я плохая $<\ldots>$ Мне нужно уйти» (57), - твердит Галя). В конечном итоге девочка умирает, только так ей удается «вырваться» от материнского произвола («...произведение матери, детище и дело ее рук, полностью ее творение - ан нет, ушла, вырвалась $<\ldots>$..» $(60))$.

Таким образом, в женских текстах с ярко выраженной линией материнско-дочерних отношений мы сталкиваемся с разыгрыванием одних и тех же, одинаково организованных материнских сценариев, что позволяет нащупать некую общую болевую точку женской прозы. «Материнское» в разной степени сопряжено с подавлением, контролем и подчас диктатом, в нем нет места для проявления дочернего женского Я («...детство я запомнила как сопротивление тиранству», признается протагонистка в рассказе Ирины Васильковой «Садовница» ${ }^{14}$ ). Матери, навязывая свою волю и всячески препятствуя жизненному выбору дочери, сдерживают любые проявления ее самостоятельности. Отмеченная закономерность провоцирует на поиск причин ее возникновения. Адекватным в данном случае может быть выбор психоаналитического подхода в качестве инструмента анализа.

В частности, то обстоятельство, что мать ассоциируется в сознании героинь с властью и запретом, а дочь, в свою очередь, не может «отделиться» от нее, чтобы обрести свою собственную женскую идентичность, коррелирует с психоаналитической интерпретацией процесса женского становления, в котором фигура матери играет определяющую роль. В работах по психоанализу прослеживается мысль о том, что девочке намного сложнее, чем мальчику, «отмежеваться» от матери, чтобы обрести самостоятельность, поскольку она «идентифицируется со своей матерью <...> для того чтобы достичь своей женской идентификации и освоить свою взрослую, обусловленную полом роль. При этом она должна быть достаточно дифференцирована, чтобы взрослеть и ощущать 
себя в качестве отдельного индивидуума, то есть преодолеть первичную идентификацию» ${ }^{15}$. Речь идет о первой стадии женской инициации, которую переживает каждая девочка с наступлением половой зрелости, когда ей предстоит отказаться от «материнской телесной опеки» ${ }^{16}$, чтобы осознать свою предначертанную полом роль.

По словам немецкого психоаналитика Евы Полюды, «девочка, теряя мать, умирает как ребенок и рождается как женщина, если все проходит благополучно» ${ }^{17}$. Иначе, как показывают представители психоанализа, женщина остается в постоянной зависимости от матери, постоянно идентифицируясь с нею, что мы и можем наблюдать в анализируемых текстах. Героини всех произведений в той или иной степени не достигли обособленности от «материнского» опыта, они живут с постоянной оглядкой на мать, всегда ощущая свою слитность с ней. Подчас травматичная для обеих симбиотическая связь буквально носит психофизиологический характер. В романе О. Славниковой «Стрекоза, увеличенная до размеров собаки» (1997) мать и дочь будто всю жизнь сторожат друг друга, даже во сне: «...когда мать и дочь сторожили друг друга, безнадежно понимая, что жизни их сцепились и застряли, желая не то разойтись, не то окончательно совместиться, чтобы засыпать одновременно, с легкостью свободного, самому себе предоставленного существа» ${ }^{18}$. Возможно, именно поэтому возникающий в некоторых произведениях мотив дочернего «освобождения» непосредственно связан с мотивом смерти матери, возникающего в качестве единственного шанса стать на путь обретения собственной самости (например, в рассказе Л. Петрушевской «Круги по воде», И. Васильковой «Садовница», в романе О. Славниковой «Стрекоза, увеличенная до размеров собаки» и др.).

В аспекте психоаналитической интерпретации материнско-дочернего сюжета более ясным становится и постоянно сопровождающее героиню и первоначально, казалось бы, не поддающееся мотивации чувство безотчетной вины, которое является, прежде всего, следствием бессознательной дочерней агрессии, подсознательной ненависти по отношению к матери в случае непреодоленной зависимости от нее ${ }^{19}$. Ощущением вины по отношению к матери в разной степени наделены героини большинства упомянутых произведений, в которых на первый план выступает художественное осмысление дочерних чувств.

Показательна в этом смысле фраза, служащая характеристикой компенсационного характера дочернего отношения в упомянутом рассказе «Отдых»: «Она никогда не расставалась с ней, поэтому не может вспомнить такой радости при встрече, какую увидела сейчас у этой институтки. Но, конечно, она любила свою бедную, худенькую мать. Она до сих пор не может без нежности вспомнить о ней! < ..> Уже после смерти матери Марья Ниловна свила около нее какой-то венчик, и память о ней стала для нее священной; а при жизни она, должно быть, тяготилась ею» ${ }^{20}$.

В произведениях Летковой чувство вины возникает, главным образом, все из-за той же «боязни огорчить мать», опасения не угодить ей, не оправдать ее ожидания, а отнюдь не из-за каких-либо объективно неправильных и ошибочных поступков героини. То же чувство постоянно сопровождает героиню повести «Мертвая зыбь» (1897) по мере отдаления от матери и попыток выйти из-под ее опеки. Не случайно в героине постепенно пробуждается нежность к матери, которую она покинула: «Бедная, бедная мама. Как я ее люблю и как мне ее жалко. Любила ли она когда-нибудь? < ..> Дело и дочь - вот чему она отдала себя. Бедная, милая мама» ${ }^{21}$.

В уже упомянутой повести М. Крестовской «Вне жизни», героиня Женечка не может покинуть свою мать, выбрав свой путь, из-за терзающего чувства вины перед ней. В рассказе современного автора Ирины Васильковой «Садовница» взрослая дочь, от имени которой ведется повествование, замечает за собой «невероятное, выматывающее чувство вины» перед матерью, немотивированное внешними причинами.

Между тем, характеризуя категорию вины, которая используется многими психоаналитиками, исследующими роль матери в становлении личности ребенка, следует указать на различные ее толкования. Так, например, известный немецкий психоаналитик X. Дейч, анализируя отношения «мать - дочь» приходит к выводу о том, что привязанность дочери к матери в основном является компенсацией того подсознательного чувства ненависти, которое испытывает девочка в период становления собственной идентичности ${ }^{22}$. Согласно теории М. Кляйн, чувство вины по отношению к матери свойственно детям обоего пола и наступает на определенном этапе взросления ребенка, являясь следствием осознания им ранней подсознательной агрессии, направленной на мать в первый год жизни. Иначе говоря, вина - это своего рода защита от негативного образа матери на более поздней стадии развития, когда «ребенок испытывает чувство вины из-за боли, причиненной им матери, проявляет заботу и тревогу о ней» ${ }^{23}$. Возможно, поэтому в текстах писательниц мы находим выражение экзальтированной привязанности ребенка к матери.

В повести Летковой «Чудачка» (1898) большую роль играют детские впечатления героини, которые свидетельствуют о том, что свою подчиненность матери она ощущает с раннего возраста. Гипертрофированное чувство дочерней привязанности неоднократно акцентировано в тексте. Так, Марина признается себе в том, что с четырех лет «она существует для матери» ${ }^{24}$. Зародившееся в детстве чувство зависимости от матери сохраняется у героини и в сознательном возрасте, сдерживая проявление самостоятельности.

Подобная трактовка проблемы встречается в творчестве других писательниц конца XIX - на- 
чала XX в., например М. Крестовской (повесть «Вне жизни» (1887), рассказ «Иса» (1885), повесть «Ранние грозы» (1886)). Знаменателен и общий для текстов Летковой и Крестовской дискурс психофизиологической привязанности к матери в детском возрасте, граничащей с обожанием. Так, в повести Летковой «Чудачка» героиня, будучи взрослой, «до сих пор помнит, с каким восторгом она смотрела на мать, $<\ldots>$ в матери ее все восхищало и умиляло. Она чувствовала себя такой ничтожной перед ней, что готова была ей ноги целовать» ${ }^{25}$. Ср. у Крестовской: Наташа, девочка-подросток в повести «Ранние грозы», «положительно была влюблена в свою красавицу мать. Она, как и в пять лет, осталась для нее все тем же лучезарным кумиром, предметом страстного обожания» ${ }^{26}$. Похожее чувство восхищения матерью мы обнаруживаем в рассказе О. Ольнем «Радость (из дамского дневника)» (1904), написанном в форме воспоминаний от лица героини преклонного возраста. Вспоминая детские годы в родительском доме, она приводит свои впечатления от матери: «Свою мать я боготворила. Любовь к ней граничила у меня с экзальтированным обожанием. Она была моим кумиром, моим идеалом. У меня в голове не поместилась бы даже мысль о том, что она может оказаться неправой, злобной или несправедливой» ${ }^{27}$. В рассказе современного автора Ирины Васильковой «Садовница» присутствует тот же мотив: протагонистка, вспоминая свои детские впечатления от общения с матерью, сравнивает себя с «маленьким пажом» перед матерью, которая казалась ей Марией Стюарт или Маргаритой Наваррской («...во фрейлины меня, конечно, не взяли бы, но, может, разрешили бы стать маленьким пажом и расчесывать волосы по утрам. Этой процедурой я упивалась бы - ведь только потом поняла, как не хватало тактильных ощущений в детстве»).

Итак, мы можем наблюдать, что в женских литературных текстах многосторонне разрабатываемая проблема материнского воздействия на дочь, которая движима готовностью к практически безотчетному подчинению психологической власти матери, становится ярко выраженной линией в процессе художественного конституирования женского сознания и репрезентации женского субъекта. Причем в творчестве некоторых писательниц эта проблема приобретает сквозной характер и находит наиболее последовательное воплощение, как это происходит в произведениях Летковой. Отношения матери и дочери в ее текстах всегда драматичны, и хотя иногда писательница приводит их к благополучному итогу, примирение выглядит лишь как преодоление мировоззренческого разлада (например, в повестях «Мертвая зыбь», «Чудачка»). Здесь память приходят слова швейцарской исследовательницы-психоаналитика юнгианской школы Сибилл Биркхойзер-Оэри: «Женщине следует понять, что она является лишь сценой, на которой разыгрывается драма взаимо- отношений матери и дочери, а вовсе не актрисой, исполняющей ту или иную роль» ${ }^{28}$.

Действительно, психологический портрет героини, изображенный в творчестве упомянутых писательниц, становится своего рода слепком ее взаимоотношений с матерью, которые представляют собой один из описанных в психоанализе вариантов развития женской личности. Очерченные грани репрезентации образа матери провоцируют задуматься о причинах или предпосылках именно такого ракурса художественного видения этой стороны человеческих взаимоотношений, а главное, того, что за ним скрывается - индивидуальный психологический опыт, трудности переживания стадий женской инициации или пробуждение некоей общей женской памяти, сокрытой в глубинах подсознания, того, что на языке юнгианского психоанализа носит название «коллективного бессознательного». Возможно, релевантными в данном случае оказываются теории последователей Юнга, выдвигающие на первый план теории материнского архетипа, актуализирующего область бессознательного.

Закономерно также предположить, что корни проблемы нужно искать в гендерно дифференцированном воспитании, что оборачивается для женщины «нелюбовью» к матери. В частности, имеет место описанная еще Фрейдом и поддержанная некоторыми представительницами постфрейдовского психоанализа ситуация травмы, которую вынуждена переживать девочка в процессе своего психического формирования, когда ей нужно отказаться от матери в качестве объекта любви в пользу отца, чтобы обрести собственную женскую идентичность ${ }^{29}$. Так или иначе, писательницы фиксируют некий общий архетипический сюжет «любви-ненависти» между женщинами на уровне родового начала. И важно то, что в подавляющем большинстве рассматриваемых текстов отношения матери и дочери представлены изолированно от фигуры отца, который зачастую отсутствует в материнско-дочерних сюжетах (из рассмотренных текстов исключение составляет рассказ И. Васильковой «Садовница»). Другой вопрос, какие смыслы заключает это повторяющееся в женском письме противоборство двух женских начал - матери и дочери? Запечатление неких глубинных подсознательных структур, по выражению Л. Иригарей, женского «подполья нашей истории» ${ }^{30}$, преодоление через письмо подсознательно затаившегося конфликта (подобная интенция артикулирована в рассказе Васильковой) или выражение надежды на восстановление истинной женской генеалогии, построение женской этики, свободной от патриархатных законов? На эти вопросы еще предстоит дать ответы. Так или иначе, очевидно одно: эстетически воплощенное переживание сложной, амбивалентной, первоосновной связи «мать - дочь», зафиксированное писательницами разных литературных эпох, позволяет видеть специфичность творческого самораскрытия женского субъекта. 
12 См. об этом: Gambaroff M. Utopie der Treue. Hamburg, 1990.

13 Петрушевская Л. Круги по воде // Петрушевская Л. Черная бабочка : рассказы, диалоги, пьеса, сказки. М., 2008. Далее текст цитируется по этому изданию с указанием страницы в скобках.

14 Василькова. И. Садовница // Новый мир. 2007. № 7. URL : http://magazines.russ.ru/novyi_mi/2007/7/va4.html (дата обращения: 18.02.2013). В дальнейшем цитаты в тексте приводятся по этому источнику.

15 Чодороу Н. Воспроизводство материнства: психоанализ и социология пола (часть III. Половая идентификация и воспроизводство материнства) // Антология гендерной теории : сб. пер. / сост. и коммент. Е. И. Гаповой, А. Р. Усмановой. Минск, 2000. С. 35.

16 Полюда Е. «Где ее всегдашнее буйство крови?» Подростковый возраст женщины : «Уход в себя и выход в мир» / Пол. Гендер. Культура. Вып. 3. С. 105.

17 Там же. С. 109.

18 Славникова О. А. Стрекоза, увеличенная до размеров собаки : роман. М., 2006. С. 34.

19 См.: Полюда Е. Указ. соч. Вып. 3. С. 101-135.

20 Леткова Ек. Отдых. С. 188.

21 Леткова Ек. Мертвая зыбь : Повесть // Русская мысль. 1897. № 11. C. 44.

22 См.: Роде-Даксер К. Образ матери в психоанализе // Пол. Гендер. Культура. Вып. 3. С. 80.

23 Там же. С. 85.

24 Леткова Ек. Чудачка // Русская мысль. 1898. № 11. С. 189.

25 Там же. С. 187.

26 Крестовская М. Ранние грозы // Русский вестник. 1886. C. 671.

27 Ольнем О. Радость (из дамского дневника) // Русское богатство. 1904. № 3. С. 202.

28 Биркхойзер-Оэри С. Мать : архетипический образ в волшебной сказке : пер. с англ. 2-е стереотип. изд. M., 2010. C. 45.

29 См.: Роде-Даксер К. Указ. соч. С. 77-101.

30 Иригарей Л. Этика полового различия / пер. с фр. А. Шестакова, В. Николаенкова. М., 2004. С. 93.

11 Петрушевская Л. Время ночь // Петрушевская Л. Жизнь это театр : Рассказы, роман. М., 2009. С. 326.

УДК 821.112.2(436).09-32+929Шницлер

\section{ЖЕНСКИЕ ОБРАЗЫ В ПРОЗАИЧЕСКИХ ПРОИЗВЕДЕНИЯХ АРТУРА ШНИЦЛЕРА: ПРОБЛЕМА ДИЛЕТАНТИЗМА В ИСКУССТВЕ}

\section{Е. А. Зюбина}

Марксовский филиал Саратовского государственного социальноэкономического институт Российского экономического университета им. Г. В. Плеханова

E-mail: dudkovaliza@rambler.ru

В статье рассматриваются новеллы австрийского автора рубежа XIX-XX вв. Артура Шницлера, раскрывается важность понятия дилентантизма для автора и анализируются образы женщин, занимающихся искусством, которые в прозе Шницлера показаны исключительно как дилетантки, ломающие комедию как на сцене, так и в жизни.

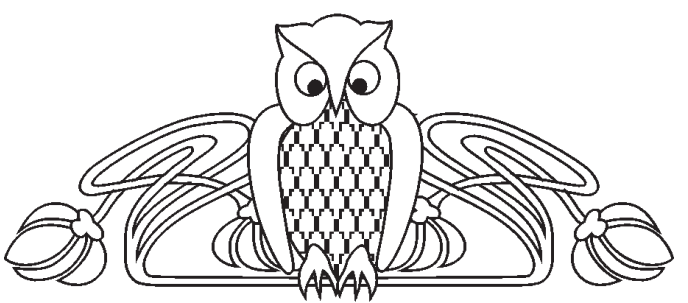

Ключевые слова: австрийская литература рубежа XIX-XX вB., Артур Шницлер, дилетантизм, женщина в искусстве.

\section{Women's Images in the Prose of Arthur Schnitzler:} the Concept of Dilettantism in Art

\section{E. A. Zyubina}

The article considers short stories by an Austrian author of the turn of the XIX and XX centuries, Arthur Schnitzler. The importance of the dilettantism concept for the author is revealed; the images of women 